\title{
Page Kidney
}

National Cancer Institute

\section{Source}

National Cancer Institute. Page Kidney. NCI Thesaurus. Code C114802.

Hypertension resulting from activation of the renin-angiotensin system in response to

prolonged compression of the renal parenchyma and blood vessels. 